\title{
Management of Rhinophyma on the basis of different excision procedures
}

Gaurav Biswari ${ }^{1}$, Pragati Gupta ${ }^{2}$, Dilip Das ${ }^{3}$

${ }^{1}$ Lecturer and In-charge, ${ }^{2}$ Medical Officer, ${ }^{3}$ Lecturer. Department of Dental Surgery, College of Medical Science, Bharatpur, Chitwan, Nepal

\begin{abstract}
The aim is to get better cosmetic results after the excision of rhinophyma because there are various procedures to excise rhinophyma in which Electrocautery is the most convenient and can be performed under local anaesthesia also.
\end{abstract}

Key words: Rhinophyma, electrocautery, anaesthesia

\section{Introduction}

Rhinophyma is a descriptive term derived from the Greek word "rhis" meaning nose and "phyma" meaning growth. It was probably known to Greek and Arabian physicians as early as 2000 B.C. but this cannot be confirmed. In those early days there were several tuberous conditions of the nose such as Tuberculosis, Syphilis, and Leprosy which were likely confused with rhinophyma. The medical literature is silent forcenturies, but the condition is well documented in Art \& Literature. ${ }^{1}$

Rhinophyma describes the growth of the nose in some patients with rosacea. The distal part of the nose thickens up, in time it develops a knobby appearance and the pores may be significantly enlarged. ${ }^{2}$ Large superficial blood vessels sometimes develop.

Rhinophyma is a disease that typically afflicts white males between 40 and 60 years of age. It is more common in men than women, with the ratio of $12: 1$ generally reported. This condition is rarely found in blacks.

Rhinophyma is an inflammatory dermatological disorder of the skin characterized by benign hypertrophy of the adnexal sebaceous structures. ${ }^{3}$ However the aetiology is unknown, it is considered by many to the end stage of acne rosacea. ${ }^{4}$

Although many different pathogenic factors have been incriminated including impaired intestinal function, vitamin deficiency, hormonal disorders, poor skin hygiene and alcohol abuse, there is not sufficient evidence to support it. Others have proposed that a chronic infection with the parasite Demodex folliculorum may be the aetiology. ${ }^{5}$

The most common misconception is the association of alcohol with rhinophyma. In William Shakespeare's Henry IV part -2, Bardolph has become Sir John Falstaff's Corporal as well as his friend. He is described as "an arrant malmsey- nose Knave" since his nose is red, supposedly from too much wine. Other traditional terms have included brandy nose and rum nose. ${ }^{6}$

Correspondence: Dr. Gaurav Biswari

E-mail:dr_arian3@rediffmail.com 


\begin{tabular}{llll}
\hline Glandular & Fibrous & Fibroangiomatous \\
\hline Nasal & Nasal overgrowth is & The striking copper \\
enlargement is & related to increased & red nose in this \\
related to very & density of nasal & condition is related to \\
marked lobular & connective tissues & enlarged oedematous \\
sebaceous & with only a variable & connective tissues \\
hyperplasia & amount of sebaceous & containing large \\
& hyperplasia. & ecstatic veins & \\
\hline
\end{tabular}

\section{Morphologic characteristics of rhinophyma}

- Telangiectasia

- Hypervascularity

- A thick nasal cutaneous layer

- Nodularity covered by atrophic skin with expanded pores.

\section{Management}

Neither treatment is successful in end stage of rhinophyma, leaving surgery as the treatment of choice. This include primary sharp excision, electrocautery excision, dermabrasion, cryosurgery and surgery with the CO2, Argon or Nd:YAG lasers. Different surgical modalities have been proposed including total excision of the involved tissues, with either flap closure or grafting of the defect, and the partial excision of the superficial hyperplasic tissues, allowing the basal skin appendages to reepithelialize. ${ }^{7}$ Total excision of the lesion with flap closure or grafting is applicable only when the lesion is small or skin cancer is present. With extensive rhinophyma, partial excision of the lesion with re-epitheliazation is the optimal method of management.

\section{Procedures of excision of rhinophyma}

\section{Laser excision}

Over the last 10 years, the $\mathrm{CO} 2$ laser has been advocated for the treatment of Rhinophyma. This technique includes excision of gross tumour with the focused $1 \mathrm{~mm}$, spot sized, laser beam. This is followed by vaporizations and oblation of the remaining tissues with a defocused spot sized laser. Decrease intraoperative bleeding and the lessened degree of post operative pain as the two main advantages to this form of treatment. As above other forms of laser therapy are available, including use of Argon and Nd:YAG laser.

\section{Sharp excision}

Sharp scalpel and razor excision have also been described. This often results in larger blood loss, that's why many surgeons have avoided this approach. Full thickness excision followed by application of split thickness skin grafts may provide satisfactory results.

With application of split thickness skin grafts there are certain disadvantages- the first is that the junction of the normal perinasal skin with the skin graft is always obvious. Colour match is a problem as well as the graft is usually hypo pigmented in relation to the rest of the face, especially when taken from abdomen or thigh.

A full thickness graft provides better texture and colour match may be better as well, especially if obtained from other "blush" areas such as behind the ear, the lower neck, the upper chest etc. Grafts provide rapid coverage but if residual appendages left under the graft, recurrent cyst and sinus tract formation can be a problem.

\section{Electrocautery excision}

The plane is established between the involved tissue and the appropriate dermal plane, using a loop attached to the electrocautery. A combination of cutting and coagulation of the involved tissues is used to excise the abnormality. After the excision of involved tissues, 
dermabrasion using the small diamond bur is used for contouring the involved area. This technique has been proven to give excellent results.

\section{Decortications}

Rhinophymatous tissues are shaved off in layers with care taken not to injure the underline cartilage. The operator may place fingers in the nostrils or use magnification in order to halt removal of tissues once a thickness of 2-3 mm. above the upper and lower lateral cartilages and nasal bones is estimated to remove. At this point the remaining fundi of hypertrophic sebaceous glands should be sufficiently to totally re-epithelise the nose. If one stops resecting above this plane, the nose will remain bulbous; to go below it will leave raw, granulating, non-epithelising areas. Areas that are difficult to mould and refine with the scalpel can be dermabraded to achieve a better result.

Decortication has been performed using cryosurgical techniques, chemical peels, dermabrasion, the cold scalpel, the Shaw knife, the Bovie hot wire loops, the argon and $\mathrm{CO} 2$ lasers.

\section{Dermabrasion}

It is a surgical procedure that abrades successive layers of skin, permitting a controlled removal of epidermis and upper dermis to a depth sufficient to treat disease, tumour or deformity. The physiologic basis of healing after dermabrasion depends on the capacity of skin to regenerate its epidermal cover by epitheliazation through skin appendages, primarily the pilosebaceous units.

\section{Chemical peels}

There is variety of agents available, although there are dramatic differences in the techniques for applying those various acids, the histopathologic features of the chemical peels are similar. Most commonly used agents are phenol, trichloracetic acid, glycolic acids etc.

Decortication retains the overall architecture of the nose and reformation of sebaceous gland pores contributes to a more normal surface texture. Additionally the colour match of the re-epithelialized nose is closer to normal than any of the skin grafting techniques.

\section{Post-operative therapy}

Post operative care of the wound includes cleaning with hydrogen peroxide or normal saline followed by

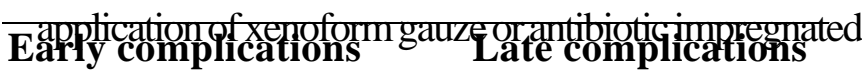
-Bdressimg. This accelerates se-enithelization as well as -Iflebridgers and protects wounfacceptable scars

$\begin{array}{ll}\text {-Bruising } & \text {-Hyper pigmentation } \\ \text {-Wound } & \text { Complications } \\ \text { problems } & \text {-Minor edge deformity } \\ \text {-Numbness } & \text { the junction of the treat }\end{array}$

\section{Case report}

A seventy two year old white male, complains of over growth of nose. Lesion appeared 2 yrs back and gradually increased in size. 


\section{Clinical features}

Due to lesion there was asymmetry of face. On palpation lesion was painless and soft. Observed hypertrophy of nasal soft tissues and two lobules of hypertrophic tissues were present on right and left side of ala of nose. General condition of patient was normal.

\section{Preparation of the patient for the surgery}

Prior to any plastic surgical procedures patient should avoid alcoholic beverages for one week prior to surgery. Anti inflammatory drugs has been stopped two weeks prior to surgery due to effect of alcohol on the body's blood clotting system.

All medical conditions and medications has discussed pre-operatively. Nasal breathing problems, Chronic running nose, allergies, prior nasal injury, and regular use of nasal sprays should be noted.

Smoking requires special mention as chemicals in smoke can cause vasoconstriction of blood vessels resulting in reduced blood supply to the re-draped and repositioned facial tissues. All smokers, regardless of quantity, are at increased risk of tissue death following face lift procedures. Patient has stopped smoking since two months before the operation in order to eliminate the added risk of tissue loss due to smoking.

\section{Investigations:}

Blood analysis- normal

Urine analysis- normal

Prothrombin index- $110 \%$

Blood sugar- $5.2 \mathrm{mmol} / \mathrm{lit}$.

ECG-normal

\section{Surgical treatment}

This lesion was extirpated under local anaesthesia; Novocain $2 \% 90 \mathrm{ml}$ was used. The method employed was electrocautery excision. First lobules which were present on right and left side of ala of nose excised with scalpel. Afterwards a combination of cutting and coagulation was used to remove hypertrophic nasal tissues and sebaceous glands. The wound was left for secondary epitheliazation. No skin graft was employed. Dressing with aminocaproic acid was given for haemostasis.

\section{Post operative care}

Post operatively routine antibiotics and pain killers, Ethamsylat $12.5 \% 4 \mathrm{ml}$ were used. First 5 days dressing with aminocaproic acid was given. After that up to 14 postoperative day antiseptic dressing was given and wound was also irrigated by $3 \%$ hydrogen peroxide solution.

\section{Discussion}

Rhinophyma begins as an accentuation of the normal flush reaction in adolescence and young adulthood and can involve the nose, central forehead, malar areas and chin. With time, the vessels of the nose become progressively dilated and the skin thickens and may become involved with the tip and the sebaceous glands hypertrophy. As the deformity worsens, pits, nodules, fissures, lobulations and pedunculations contort the nose into grotesque cosmetic problems. There is no uniformity in the end stage or final appearance.

Progression of disease in the chin has been termed as Mentophyma and involvement of pinna can lead to otophyma. Less commonly people can suffer from 
metophyma (an enlarged cushion like swelling of the forehead) or Blepharophyma (similar swelling of the eyelid).

Rhinophyma is characterized by an inflammatory process that begins with hyperaemic changes associated with hypertrophy of the sebaceous glands, followed by telangiectasias. The glands become significantly enlarged and the ducts are dilated with sebum, keratotic debris, bacteria. Few reports in the literature suggest an association between rhinophyma and basal and squamous cell carcinoma. The nasal deformity of rhinophyma also may be associated with foul odour. Histologically, sebaceous gland hyperplasia associated with newly formed connective tissues and vessels is prominent. The nasal cartilage and bone that function as the structural element are unaffected.

\section{Conclusion}

Although it is a rare case having substantial cosmetic deformity and considerable malignant potential but can be managed easily by electrocautery giving good cosmetic and favourable results.

\section{References-}

1. Plank H.P. Rhinophyma associated with carcinoma, Plastic and reconstructive surgery, Nigeria, Oral surgery 1995; 95: 559-62.

2. Thiboutot D.N. Acne rosacea new and emerging therapies, Hurchill Merley, London 2000; 18: 63-71.

3. Tope W.D., Sangueza O.P., Rhinophyma's fibrous variant, Scotland in 1934. British journal of Oral and Maxillofacial Surgery, 16: 307-31.

4. Berg M,Liden S. Epidemiological study of rosacea, Saunders, St.Petersburg, 1989; 69\{5\}:419-23

5. Cheney M.L. et al. Textbook of Facial Surgery, Plastic \& Reconstruction, Melbourne, Oxford, 1989; 23:342-5
6. Gerogiade G.S. Scott Gevin, Textbook Of Plastic \& Maxillofacial and Reconstructive Surgery, Philadelphia: Lippinncott,1967: 37: 176-81

7. Van Zuuron E.G,Gupta A.K,Hover M.D. Systemic review of rosacea treatment, Minerva Chin, Moscow, 2007;56 $\{1\} 107-115$
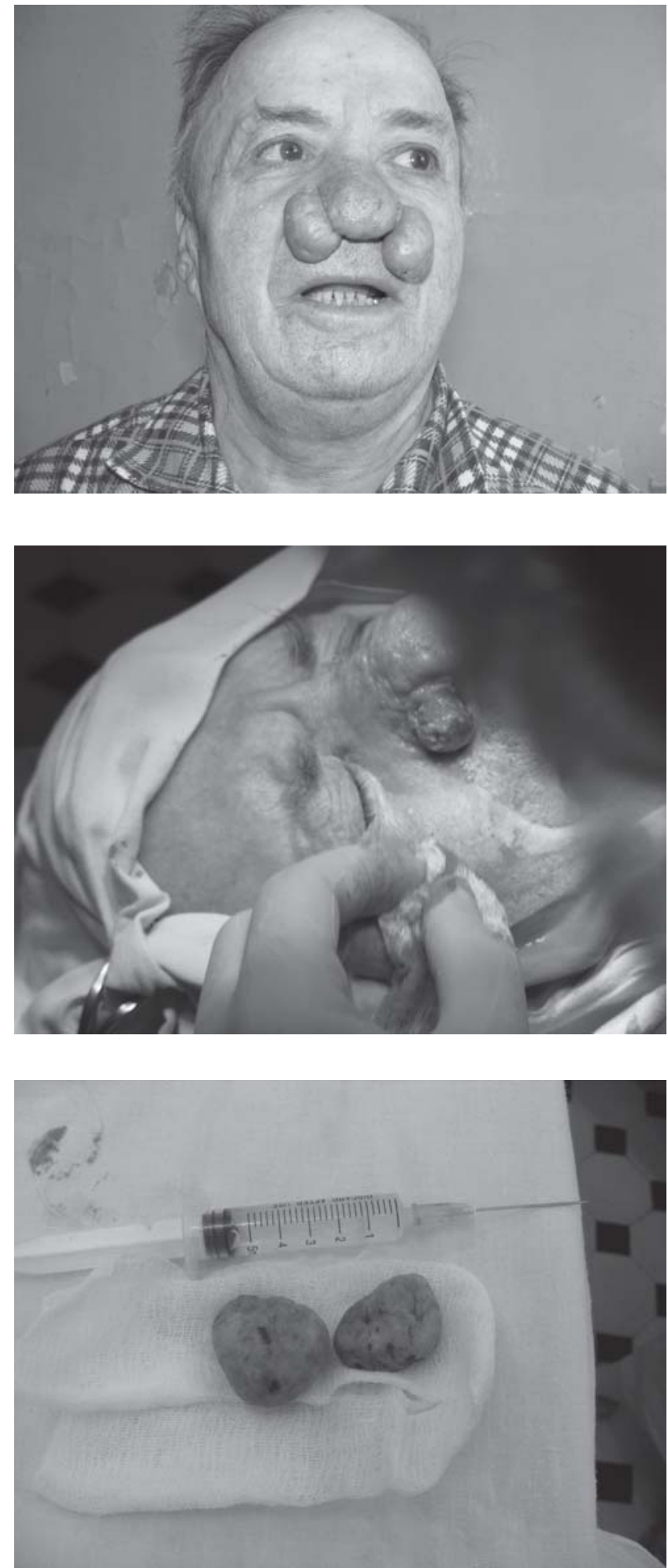
Gaurav Biswari et al, Management of Rhinophyma on the basis...
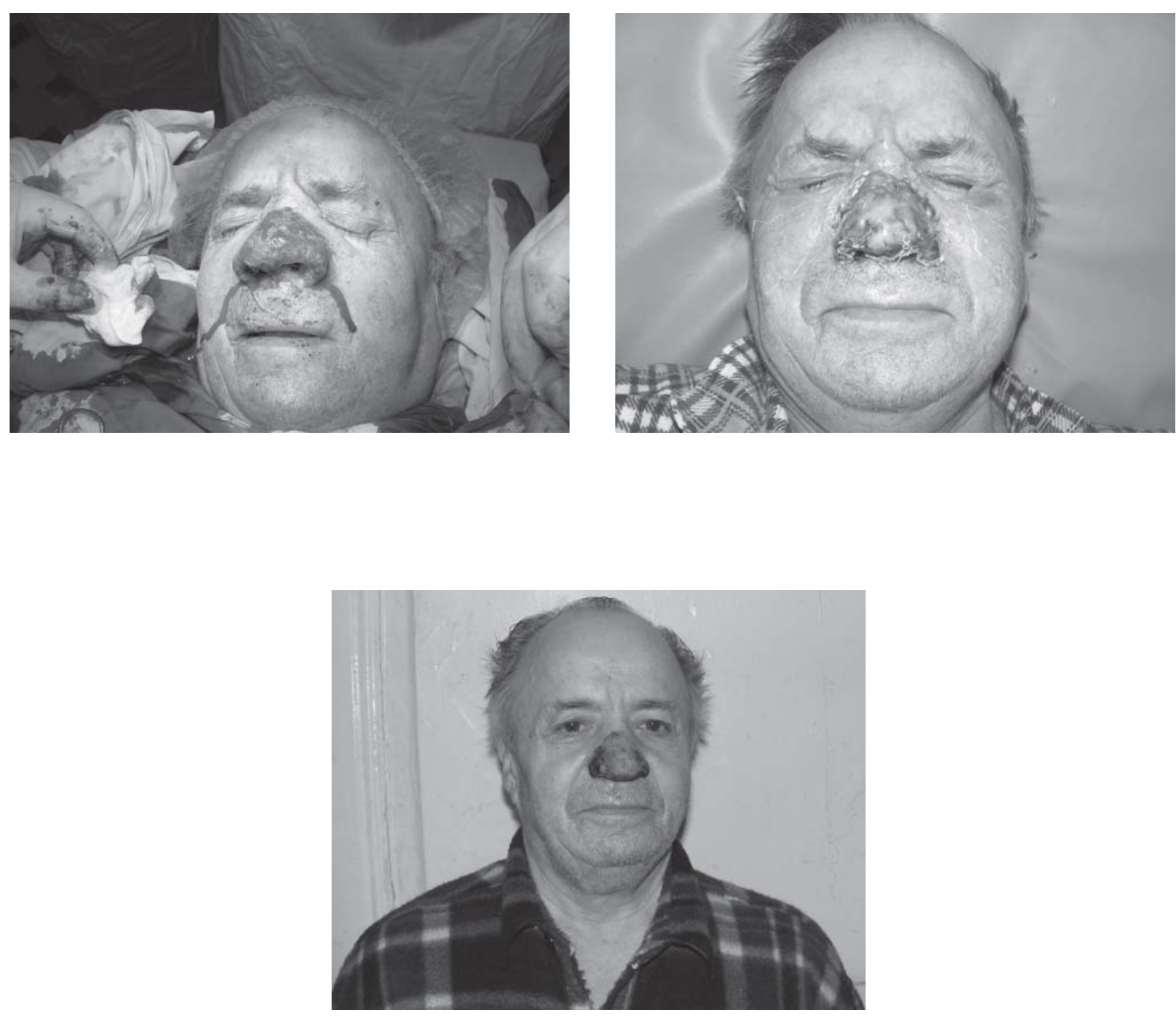